
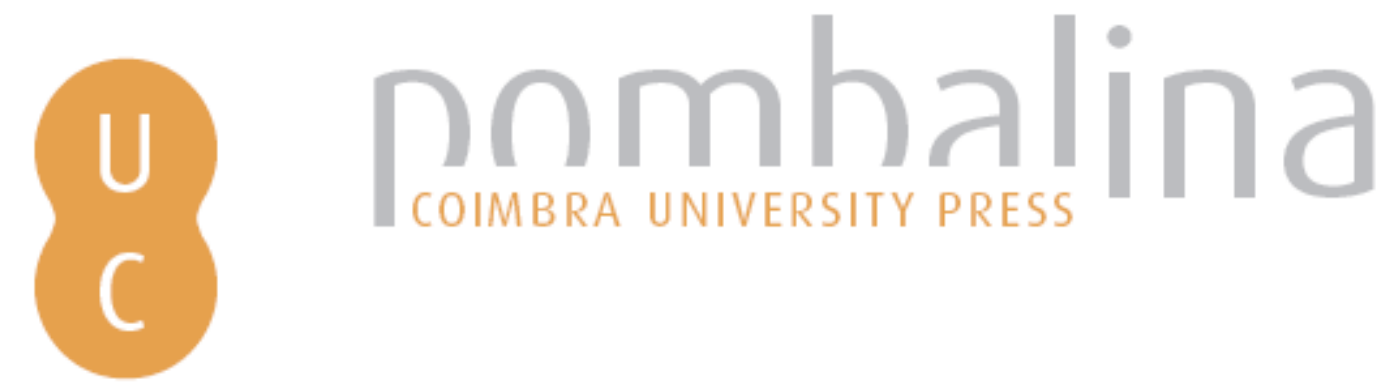

\title{
Introdução: história institucional e a reescrita permanente das estórias
}

Autor(es): $\quad$ Figueira, João; Santos, Sílvio

Publicado por: Imprensa da Universidade de Coimbra

URL

persistente:

URI:http://hdl.handle.net/10316.2/47344

DOI:

DOI:https://doi.org/10.14195/978-989-26-1778-7_1

Accessed : $\quad$ 26-Apr-2023 10:48:06

A navegação consulta e descarregamento dos títulos inseridos nas Bibliotecas Digitais UC Digitalis, UC Pombalina e UC Impactum, pressupõem a aceitação plena e sem reservas dos Termos e Condições de Uso destas Bibliotecas Digitais, disponíveis em https://digitalis.uc.pt/pt-pt/termos.

Conforme exposto nos referidos Termos e Condições de Uso, o descarregamento de títulos de acesso restrito requer uma licença válida de autorização devendo o utilizador aceder ao(s) documento(s) a partir de um endereço de IP da instituição detentora da supramencionada licença.

Ao utilizador é apenas permitido o descarregamento para uso pessoal, pelo que o emprego do(s) título(s) descarregado(s) para outro fim, designadamente comercial, carece de autorização do respetivo autor ou editor da obra.

Na medida em que todas as obras da UC Digitalis se encontram protegidas pelo Código do Direito de Autor e Direitos Conexos e demais legislação aplicável, toda a cópia, parcial ou total, deste documento, nos casos em que é legalmente admitida, deverá conter ou fazer-se acompanhar por este aviso. 


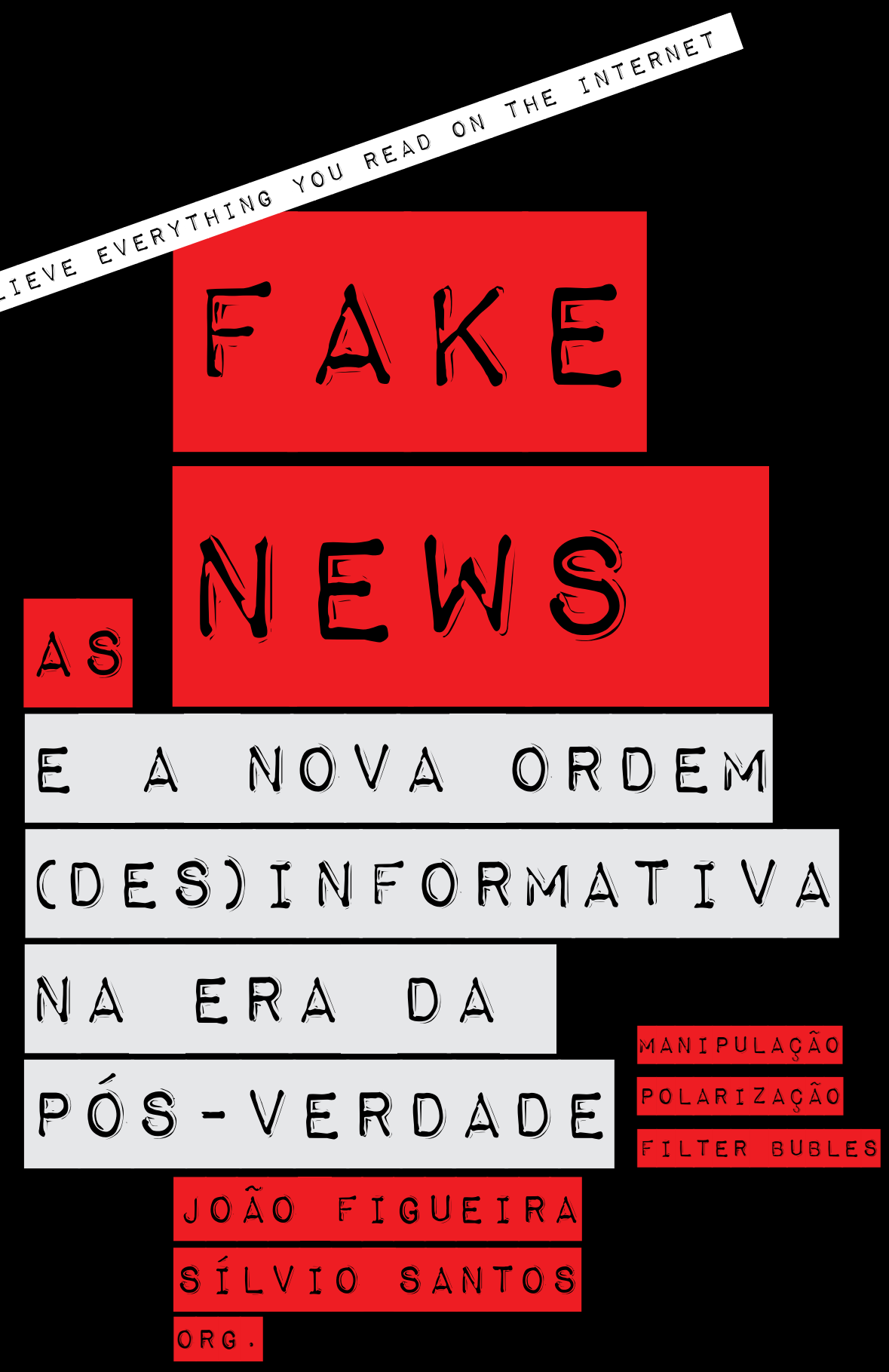

IMPRENSA DA UNIVERSIDADE DE COIMBRA

COIMBRA UNIVERSITY PRESS 
JOÃO FIGUEIRA

Universidade de Coimbra/CEIS2O

SÍLVIO SANTOS

Universidade de Coimbra/CEIS2O

\section{NT RODUÇÃO - H I STÓRIA INSTITUCIONAL}

\section{E A REESCRITA PERMANENTE DAS ESTÓRIAS}

$A$ atenção não exige verdade, mas acontecimentos ou temas que possam impor-se por efeito do seu valor informativo (Daniel Innerarity, 2006, p. 101).

Em Falsificações da história, Marc Ferro já nos alertava para o facto de que "controlar o passado ajuda a dominar o presente" (1994, p. 11), circunstância que o levava a perguntar-se: "que nação, que grupo humano, poderá controlar ainda a sua própria história?" (1994, p. 11).

Aquilo que mais sobressalta o historiador francês, quando procura saber como o cidadão comum constrói o seu conhecimento e, em última instância, como cada um de nós vai criando uma ideia ou uma imagem sobre um país, uma região, um líder - afinal, acerca de nós próprios -, a partir da informação a que se acede, é precisamente tentar perceber como a chamada "história institucional" (1994, p. 296) que é coerente com a versão dos vencedores, se impõe como verdade única e absoluta. E, assim sendo, de que maneira essa hipótese de verdade com aspirações universalistas convive com a possibilidade de existência de uma "contra-história, também ela institucional" (1994, p. 296), que corresponde à versão dos vencidos?

Para Marc Ferro, a consciência coletiva que cada sociedade tem de si mesma resulta das narrativas dominantes que, pelas razões mais diversas, se vão impondo em cada momento histórico. Mutatis mutandis, as agendas 
mediáticas e a construção da atualidade noticiosa dificilmente escapam às complexas relações de poder e influência que cada conjuntura propicia e determina. E em função de cujas verdades e narrativas se realiza a informação jornalística e, com ela, a construção da memória coletiva. Daniel Innerarity atribui, aliás, aos media essa capacidade de produzirem uma "certa memória que consiste em que podem ser considerados adquiridos determinados aspetos da realidade sem necessidade de os justificar ou de estabelecer um consenso explícito” (2006, p. 101).

Pensemos na política, essa "forma de fazer coisas com palavras", como Daniel Innerarity, inspirado no título do livro de John Austin, a classifica na sua última obra, A política em tempos de indignação (2016 p. 121). Reatualizando o pensamento de Platão, que via entre a verdade e o poder um insanável conflito de interesses, ao ponto de considerar que as pessoas preferem o que é popular à verdade, hoje a retórica política continua a manter-se nesse equilíbrio instável onde a imprecisão da linguagem está ao serviço da persuasão e da construção de pós-verdades. A discussão está longe de ser nova, porque o exercício da política - e tal implica o uso estratégico da linguagem - à semelhança do emprego do conceito de verdade, são membros do mesmo condomínio. Isto é, fazem parte da luta pelo poder e, nesse sentido, são incompatíveis (Rawls, 1999).

A 20 de janeiro deste ano, o Fact Checker do Washington Post ${ }^{1}$ noticiava que nos dois primeiros anos de mandato, Donal Trump divulgou 8158 notícias falsas ou enganosas, "como se a arte de governar não fosse mais que a capacidade de enganar os outros e o exercício do poder estivesse irremediavelmente ligado à mentira" (Innerarity, 2016, p. 122). A verdade, é que com a chegada de Trump à Casa Branca, a utilização do Twitter por atores políticos ganhou um protagonismo e uma presença sem precedentes.

Em junho de 2002, antes, portanto, da entrada em cena das redes sociais que hoje dominam a paisagem mediática, o conhecido jornalista da CBS, Dan Rather, afirmava com a autoridade do seu percurso profissional de quatro déca-

1 Disponível em https://www.washingtonpost.com/politics/2019/01/21/presidenttrump-made-false-or-misleading-claims-his-first-two-years/?noredirect=on\&utm_term $=.1 \mathrm{c} 58$ 652750d0 
das, em entrevista à BBC, que "o medo impede que os jornalistas coloquem as perguntas mais difíceis" (Palast, 2006, p. 322). As palavras do experiente pivô norte-americano foram produzidas no contexto pós 11 de setembro, quando era muito difícil - até perigoso - um jornalista pôr em causa a tal "história institucional" veiculada sem provas nem evidências pela Casa Branca. Veio a saber-se, anos mais tarde, que a referida "história institucional" sobre as armas de destruição massiva não tinha passado de uma bem montada campanha de manipulação de informação (Lewandowsky et al., 2013).

A manipulação, enquanto fenómeno que visa construir artificialmente uma dada realidade, inscreve-se na noção mais ampla de desinformação proposta por Vladimir Volkoff: consiste na "manipulação da opinião pública para fins políticos através de informação trabalhada por processos ocultos" (Volkoff, 2000 , p. 31). É este o contexto do qual as fake news são e sempre foram parte. Note-se que as fake news hoje são apenas uma parcela do mais amplo problema da "desinformação". Wardle e Derakshan (2017, p. 5) distrinçam bem os vários lados do problema que hoje estão em jogo: erros não intencionais (sempre existiram e quase sempre são corrigidos) são apelidados por Wardle e Derakshan de mis-information; desinformação (dis-information) refere-se a toda a informação que é divulgada com a consciente intenção de causar prejuízo - e na qual as fake news se integram; e, por último, a chamada mal-information, que se refere a informação verdadeira que é divulgada com intenção de causar dano. Na verdade, estas categorias não representam nada que seja originário da era da comunicação em rede. Hoje, no entanto, a manipulação da opinião pública, na expressão de Volkoff (2000), já não se circunscreve apenas ao campo da política. Claro que esse continua a ser o mais relevante e o que mais meios e atenção mobiliza; porém, o debate acerca das fake news é hoje recentrado por três fatores fulcrais: a ascensão de protagonistas estranhos ao campo da política que agora dominam o espaço público mediatizado, o papel das redes sociais e da internet e a crescente sensação de relatividade perante os factos, usando a expressão de Mihailidis e Viotty (2018).

Estudos recentes mostram, aliás, que no atual ambiente digital marcado pela influência das redes sociais, é através do Facebook que se verifica o maior tráfego de informação, embora as chamadas hard news circulem prefe- 
rencialmente através do Twitter (Anderson \& Caumont, 2014; Phillips, 2015 e 2012). Angela Philips (2012) considera, de resto, que aos antigos pilares noticiosos da verdade e legibilidade/compreensão das notícias, é imprescindível juntar hoje a vertente da partilha e da sociabilidade, para que a informação seja viral. Nesse sentido, observa que "o aparecimento do Twitter aumentou exponencialmente a velocidade de disseminação da informação, a partir de uma só fonte" (2012, p. 670).

Previsões feitas há mais de uma década, nos alvores das redes sociais, e talvez por esse motivo ainda enfeitiçadas pela novidade do fenómeno, viam nessa nova possibilidade de comunicação trazida pela rede uma mudança radical nos processos de produção e distribuição de informação (Gillmor, 2005), ao ponto de se achar que estaríamos na antecâmara de uma revolução no interior da própria democracia.

A revolução do User-Generated-Content trazida pela web 2.0 significou o fim das barreiras no acesso à comunicação em grande escala, o que foi potenciado pelas dinâmicas trazidas pelas redes sociais. O enorme impacto desta revolução só foi possível porque a informática de consumo se tornou economicamente acessível, particularmente as plataformas móveis, que se tornaram verdadeiramente omnipresentes no quotidiano das sociedades mais desenvolvidas. Porém, seria redutor circunscrever a mudança à democratização do acesso à tecnologia. A convergência, como explica Jenkins (2006, p. 3) ocorre no cérebro dos utilizadores e não nos seus aparelhos. Falamos, pois, de uma sociedade que hoje está permanentemente conectada, que constrói e faz circular o conhecimento de forma diferente.

Hoje, qualquer pessoa pode produzir (e distribuir) informação falsa (Southwell et al., 2018; Jenkins, 2006), fruto do novo paradigma da comunicação que marca o fim do velho monopólio em que os mass media viveram durante mais de um século, porquanto vivemos, agora, na expressão de Manuel Castells, numa sociedade de "autocomunicação de massas" (2015, p. 28). Tal significa que um indivíduo, sem formação específica na construção de informação ou, sequer, reputação, pode em muitos casos superar o número de leitores que órgãos de comunicação tão influentes como a CNN, Fox News ou The New York Times atingem (Allcott \& Gentzkow, 2017). Em todo o caso, como sublinha Philips (2012) observando a realidade do Reino Unido, continuam a ser 
os grandes media como a BBC, Daily Mail, The Guardian e Sky que dominam o tráfego noticioso, tanto na procura como na divulgação.

Não sendo, portanto, as fake news um fenómeno inteiramente novo, a sua discussão e análise ganhou, com o outro lado da mesma moeda que é a pós-verdade, uma renovada atualidade e relevância. Na verdade, os possíveis impactos da desinformação divulgada através da internet durante as últimas eleições nos Estados Unidos da América e, mais recentemente, na Catalunha, trouxeram as fake news e a desinformação para o centro das agendas política e científica. O próprio espaço público abriu-se à discussão acerca deste fenómeno. O Collins Dictionary, após verificar um aumento de 365\% do uso online desta expressão, escolheu fake news como "Palavra do Ano 2017".

É neste contexto que propomos, através da presente edição, um olhar alargado e diverso sobre tais tópicos, juntando as reflexões e pesquisas de um importante conjunto de investigadores portugueses e brasileiros de mais de uma dezena de universidades dos dois países. É, efetivamente, um momento muito particular para pensar no significado da verdade e da democracia, na importância da informação como fator de empoderamento cívico, no papel do jornalismo e nos desafios que o afrontam e o colocam em risco tal como o conhecíamos no final do século passado. É um momento decisivo para se questionar o papel da informação numa sociedade que se ergueu precisamente sobre o valor do conhecimento.

Esperamos, pois, que nesta obra o/a leitor(a) encontre motivos suficientes para questionar e problematizar um tempo em que a informação, apesar de mais abundante e omnipresente que nunca, de ser consumida numa voragem aparentemente incompatível com a profundidade e a explicação, implica cada vez mais um exercício de prudência, desconfiança e verificação.

O texto inaugural de Ciro Marcondes Filho alerta-nos para o quão fundo a desinformação nos pode levar. Num tempo de total submissão à tecnologia, o abandono do pensamento estruturado e fundamentado em favor do imediatismo comunicacional constituiu-se como o terreno perfeito para a nova era da circulação multidirecional da informação. "O pensamento místico-tecnológico do século atual assinala essa descrença no discurso iluminista e o retorno de soluções místicas, seja pelo retorno da crença de salvação nas religiões, seja na subserviência total às tecnologias e às políticas que se propõem a 
resgatar um paraíso perdido das nações”. O buraco em que as fake news nos podem fazer cair é, como diz Marcondes Filho, bem mais profundo do que poderíamos pensar.

A primeira parte do livro propõe uma contextualização das fake news e, de forma mais aberta, da própria desinformação. Principia com uma reflexão de Juremir Machado da Silva, que trata o problema das fake news à luz do pensamento de Jean Baudrillard e de Umberto Eco. É o retrato de um tempo em que a verdade surge fragilizada pelo relativismo e no qual a falsificação conseguiu o seu maior aliado - a velocidade: "num tempo em que o relativismo não pode mais ser negado pela verdade do especialista, pois sempre pode existir outro especialista para sustentar o oposto, só a falsificação se dispõe a apresentar uma 'verdade' incontestável".

Carla Baptista propõe-se analisar as condições históricas que fragilizaram o jornalismo que, à conta de uma difícil adaptação às dinâmicas da digitalização, não foi capaz de impedir a perda de intenção, nitidez e qualidade da sua informação. Numa esfera pública que se degradou profundamente, “a desinformação generalizada é um dos principais sintomas da patologização aguda da vida comunicativa coletiva". O enfraquecimento da "função mediadora do jornalismo" - alerta a professora da Universidade Nova de Lisboa - só pode ser compensado com o desenvolvimento de cidadãos conscientes, "dispostos a interagir criticamente com os media".

É nas redes sociais que as notícias falsas encontram as melhores condições de circulação. Inês Amaral e Sofia José Santos debruçam-se, precisamente, sobre esse campo, dominado por novos atores, livres de qualquer intermediação obrigatória por parte dos outrora imprescindíveis gatekeepers. Este é um processo tão promissor quanto perverso, que enfatiza a imprescindibilidade de uma consciência plena sobre o novo ecossistema mediático e os perigos de uma "substituição [generalizada] de evidências por crenças pessoais e emoções".

As pessoas têm de poder confiar no jornalismo, como explica Muniz Sodré: tem de haver "confiança pública na veracidade dos fatos para a sustentação da democracia representativa”. Esta questão já não é nova, como explica o autor no seu capítulo, no entanto, há uma indiferença cada vez maior em relação aos factos, que parecem ser progressivamente secundarizados em relação às 
emoções, num contexto em que as redes sociais desafiam quotidianamente a credibilidade informativa.

É, precisamente, dando continuidade a esta tendência, geralmente descrita como pós-verdade, que se desenvolve um conjunto de contribuições que problematizam, questionam e interpelam o/a leitor(a) em relação ao valor da verdade, ao papel dos media, da tecnologia e daqueles - agora tantos - que produzem opinião em relação aos factos, criando as condições ideais para que o Outro seja olhado com desconfiança e descrédito.

A instigante reflexão de Alexandre Franco de Sá, denuncia esta crescente dicotomia, num mundo dividido entre o bem e o mal, fruto de uma incessante circulação de informação que é simplificadora e manipulativa. Estabelecendo um caminho que nos leva ao tempo da pós-verdade, o autor alerta que "este não é senão o ponto em que, como consequência da manipulação mediática, se torna explícito o que já há muito tinha sido caracterizado como um perigo: a desconfiança e a recusa de acreditar em qualquer verdade".

Hélder Prior explica como as características da comunicação em rede, na atualidade, têm favorecido o crescimento de retóricas populistas - surgidas tanto à esquerda como à direita no espectro político. Neste capítulo é analisada a associação entre os populismos, a polarização ideológica e a própria ideia de pós-verdade, num tempo de crise de confiança na política e na justiça.

Perante este cenário, o que tem feito o jornalismo, particularmente, o ciberjornalismo em favor da verdade? No ensaio de Fernando Zamith, somos confrontados com a ideia de que talvez não tenha sido muito. Talvez o jornalismo se tenha andado a contentar com porções de verdade - "pós de verdade", no jogo de palavras que o autor propõe. É, porém, ao jornalismo e a outras instituições tradicionalmente conotadas com a defesa dos factos que cabe uma imprescindível investida para reconquistar a importância da verdade.

Luís António Umbelino recupera a ideia da colonização dos media pela simplicidade - não pela simplicidade da forma, mas pela redutora simplificação do conteúdo. Como podemos compreender a crescente vacuidade do contexto mediático? Como entender a crescente tendência para concluir antes de pensar? Neste ensaio, Umbelino retrata um quotidiano informativo no qual as preocupações técnica e comercial soterraram qualquer molde assente no aprofundamento informativo. É um contexto facilmente reconhecível em tan- 
tos ecossistemas mediáticos, em que despontam formadores de opinião muito tipificáveis.

O derradeiro conjunto de capítulos deste livro analisa casos mais particulares. Desde as mais publicitadas situações ocorridas no âmbito de processos eleitorais - com foco nas eleições presidenciais brasileiras de 2018 -, às perceções que os jornalistas têm de toda esta situação, terminando com um olhar sobre a forma como a educação é um pilar central de qualquer resposta ao problema.

É, precisamente, com um caso sucedido durante a eleição do presidente brasileiro, que Antônio Fausto Neto se propõe analisar modos de produção e de circulação de fake news com propósitos ideológicos na sociedade em rede. As fake news, como escreve o autor, "resultam destas novas conformações em um cenário paradoxal no qual quanto mais a sociedade se midiatiza mais ela se torna complexa. Quanto mais rede, mais 'zonas de sombras' se instalam nos veios em que circulam e se transformam sentidos".

No Brasil, justamente, quais as medidas que foram tomadas para fazer face à intensificação da desinformação durante as eleições? É esta a pergunta que Egle Müller Spinelli e Daniela Osvald Ramos colocam, a partir da constatação da vulnerabilidade existente no país. Isso deve-se ao facto de o Brasil ter uma "alta taxa de analfabetismo funcional", e de "grande parte da população consumir informação em dispositivos móveis, redes sociais e aplicativos de mensagens". As particularidades dos fluxos comunicacionais são francamente opacas para as pessoas - defendem as autoras -, que acabam por integrar as cadeias de circulação de desinformação.

Thaïs de Mendonça Jorge apoia-se no pensamento de Foucault e desloca o foco para a perspetiva do jornalismo. Através dos resultados de um questionário direcionado a jornalistas e professores de jornalismo no Brasil, a autora explora e analisa as preocupações em torno deste contexto. A abordagem que realiza é bastante abrangente e recusa a simplificação destes processos: "o processo de obtenção de conhecimento brota da complexidade do contexto social e cultural (...). Ao provocar mudanças nos indivíduos, a informação vira um elemento inseparável da estrutura deles".

O derradeiro capítulo, da autoria de Sandra Marinho, parte de uma questão que, tantas vezes, é simplificada e mesmo polarizada: a importância das 
Humanidades na formação do indivíduo. Mais particularmente, Marinho centra-se no ensino do jornalismo no ensino superior para argumentar em favor da formação em Ciências Sociais e Humanidades como princípio nuclear da promoção de um pensamento crítico, tolerante e aberto.

É, pois, este o conjunto de contributos de destacados investigadores que dão corpo à nossa proposta de reflexão sobre as fake news, sobre a desinformação e a verdade, sobre o jornalismo e o conteúdo gerado pelo utilizador na era da permanente conectividade. Porque o pensamento crítico é cada vez mais necessário como forma de combater essa urgência em concluir depressa, que Luís António Umbelino tão bem retrata.

\section{Referências bibliográficas}

AllCOTT, H., \& Gentzkow, M. (2017). Social media and fake news in the 2016 election. Journal of Economic Perspectives, 31(2), 211-236.

ANDERSON, M., \& Caumont, A. (2014, 24 de setembro). How social media is reshaping news. Pew Research Center - Fact Tank. Consultado em http://www.pewresearch. org/fact-tank/2014/09/24/how-social-media-is-reshaping-news/.

CASTELLS, M. (2015). Redes de indignación y esperanza. Madrid: Allianza Editorial. FERRO, M. (1994). Falsificações da história. Lisboa: Publicações Europa-América.

Gillmore, D. (2005). Nós os media. Lisboa: Editorial Presença.

INNERARITY, D. (2006). O novo espaço público. Lisboa: Teorema.

INNERARITY, D. (2016). A política em tempos de indignação. Lisboa: D. Quixote.

JENKINS, H. (2006). Convergence culture: Where old and new media collide. New York: New York University Press.

LEWANDOWSKY, S., Stritzke, W. G. K., Freund, A. M., Oberauer, K., \& Krueger, J. I. (2013). Misinformation, disinformation, and violent conflict: From Iraq and the "war on terror" to future threats to peace. American Psychologist, 68, 487-501.

PALAST, G. (2006). Cobardía y conflictos: El linchamento de Dan Rather. In P. Philips (Coord.), Censura: Las 25 noticias más censuradas (pp. 318-323). Perugia: Nuovi Mondi Media.

PHILlIPS, A. (2012). Sociability, speed and quality in the changing news environment. Journalism Practice 6(5-6), 669-679. 
PHILLIPS, A. (2015). Journalism in context. London: Routledge.

RAWLS, J. (1999). Collected papers. Massachussets: Harvard University Press.

SOUTHWEll, B. G., Thorson, A., \& Sheble, 1. (Eds.) (2018). Misinformation and mass audiences. Austin: University of Texas Press.

VOLKOFF, V. (2000). Pequena história da desinformação. Lisboa: Editorial Notícias.

WARDLE, C., Derakhshan, H. (2017). Information disorder. Toward an interdisciplinary framework for research and policymaking. Council of Europe report DGI (2017)09. Consultado em https://rm.coe.int/information-disorder-toward-an-inter disciplinary-framework-for-researc/168076277c 